\title{
"Travesía lunar, un cuerpo expandido" Desarrollo de un proyecto artístico sobre etapas del cuerpo femenino, imágenes arcaicas y espacio ritual
}

Adela Marín Villegas

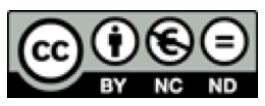

Esta obra está bajo una licencia Creative Commons

Reconocimiento-No comercial-Sin Obra Derivada 

Artículos

\title{
"Travesía lunar, un cuerpo expandido" Desarrollo de un proyecto artístico sobre etapas del cuerpo femenino, imágenes arcaicas y espacio ritual
}

\author{
Adela Marín Villegas ${ }^{1}$ \\ Universidad Veritas \\ adelamarin2@yahoo.es
}

Recibido: 16 de enero de 2016 Aprobado:18 de febrero de 2016

\section{Resumen}

Esta reflexión es el producto de una investigación que ha venido generándose durante varios años, a lo largo de mi creación artística. Partiendo inicialmente del proyecto de graduación de mi Maestría "La Ruta de la Luna" (2007), donde se establece una indagación teórico-práctica que involucra el diseño del espacio y la imagen; vinculada a los ciclos vitales del cuerpo femenino como eje motivador, que se concreta en una instalación. Y que ha sido la base conceptual para otras investigaciones creativas posteriores.

El presente texto da una nueva mirada, que se concentra mayormente en la vinculación del cuerpo a simbolismos femeninos arcaicos o arquetípicos, el inconsciente colectivo, el pensamiento mágico religioso, el mito y el rito. Partiendo de las teorías de Carl Jung, las investigaciones de Mircea Eliade, el ordenamiento de los regímenes diurno y nocturno de Gilbert Duran, referencias de artistas precursoras del arte feminista, entre otros.

Todo esto para crear un corpus teórico de referencia para la elaboración conceptual, la implementación y el análisis de esta creación artística particular.

Palabras clave: cuerpo femenino, mito, rito, inconsciente colectivo, imagen arcaica, arquetipo, investigación artística, instalación, diseño, semiótica

\begin{abstract}
This reflection is the result of an investigation that has been generated for several years, throughout my artistic creation. It was initially based on my master`s degree graduation project: "The path of the

${ }^{1}$ Artista visual costarricense. Ha sido profesora universitaria en Costa Rica, en el Instituto Tecnológico de Costa Rica y en la Universidad Veritas, en áreas de Diseño, Dibujo y Fotografía. Actualmente está en receso por beca de estudios fuera del país.
\end{abstract}




\section{Artículos}

Moon" (2007), where a theoretical and practical inquiry is established involving the design space and the image. It creates a link to the life cycles of the female body as a motivator axis, which is materialized on a particular art installation. This work has been the conceptual basis for later creative research as well. This paper gives a new observation, which focuses mostly on linking women's archaic symbolism or archetypes, collective unconscious, the magical religious thought, myth and ritual. The work is based on the theories of Carl Jung, the investigations of Mircea Eliade, the diurnal and nocturnal imaginary order of Gilbert Duran, and references of feminist art artists, among others.

All this research is intended to create a theoretical corpus of reference for the conceptual design, implementation and analysis of this artistic creation.

Key words: female body, myth, ritual, collective unconscious, archaic image, archetype, artistic research, semiotics, installation, design. 
Me convierto en una extensión de la naturaleza y la naturaleza se convierte en una extensión de mi cuerpo. Este acto obsesivo de reafirmación de mis vínculos con la tierra es realmente la reactivación de creencias primitivas... [en] una fuerza femenina omnipresente, la imagen que permanece tras haber estado rodeada por el vientre materno, es una manifestación de mi sed de ser.

Ana Mendieta (Kuspit, 1996, p.54).

\section{Introducción}

Mi preocupación como artista se ha acercado al uso y la representación del cuerpo, lo autorreferencial y lo íntimo como tema. Por ende, al trabajar la auto-representación, me ha interesado mi propia corporeidad femenina, así como el imaginario que ha sido construido alrededor de este género. El presente texto es el producto de una exploración teórica y práctica que ha sido continua durante varios años en la aplicación de diferentes trabajos artísticos desarrollados por mi persona y que tiene como uno de sus puntos de partida mi proyecto de graduación en la Maestría de Diseño del Espacio, La Imagen y El Producto (año 2007), a partir de la cual se construye una indagación que involucra los campos mencionados, vinculada a los períodos de desarrollo corporal femenino como eje temático.

Anterior a este proceso, elaboré la obra $T e-$ traktys que fue presentada a la Bienal de Arte Centroamericano en el año 2003, la cual fue uno de los primeros acercamientos a imágenes arquetípicas de lo femenino, en torno a las construcciones simbólicas de lo sagrado, la figuración y la hibridez cultural en la imagen. Estas dos obras mencionadas son el germen que da inicio a una travesía de exploración de estos símbolos para la creación de varias obras posteriores bidimensionales, tridimensionales y video-creacionales, algunas como Cantos de la Llorona, Cihuacoatl, representaciones sacras de la muerte, y otras actualmente en proceso vinculadas al agua.

Aunque una de las primeras exploraciones fue realizada hace varios años, la conjunción de elementos y la complejidad que ella involucra, me motiva a retomar los datos obtenidos y a escribir este nuevo artículo, dada la coyuntura particular de esta revista, cuyo tema es el cuerpo. Mediante este análisis, deseo hacer una especie de arqueología de la obra, para dejar memoria de un proceso concienzudo y valioso, que tuvo poca o casi ninguna divulgación y, por tanto, merece la pena tratarlo.

Ahora bien, esta investigación apunta a variables que nutren conceptualmente el desarrollo del proyecto, tales como: el análisis de símbolos arcaicos vinculados a la memoria y el inconsciente colectivo; el rito y el mito como estructuras componentes, ritos de paso en diferentes sociedades y el cuerpo femenino. Más que la obra misma concretada, lo que interesa en este escrito es dejar memoria de un proceso de búsqueda en el que se construyen proximidades interesantes entre estructuraciones simbólicas básicas y universales, las cuales están relacionadas tanto con los estudios de Mircea Eliade, historiador de las religiones, como con el concepto de inconsciente colectivo de Carl Jung, como base para crear una obra artística.

El proceso de La ruta de la Luna (obra donde se concreta un estudio más profundo que parte de esta inquietud), aborda los períodos 


\section{Artículos}

vitales y potenciales del cuerpo femenino, tales como su gestación como ser viviente, el nacimiento, la menstruación, el embarazo, el climaterio, la ancianidad y la muerte; dicho acercamiento se realiza mediante una instalación a modo de espacio ritual, con un recorrido análogo a la vida y al cambio corporal, a partir de los referentes mencionados. La obra construye una especie de viaje iniciático que involucra la experiencia de vivir, o recorrer simbólicamente, el interior del cuerpo femenino a través de las disciplinas de la expresión y la concreción: el arte y el diseño desde varios ámbitos, sobre todo, tomando en cuenta las actuales vinculaciones del diseño como disciplina en los estudios de la experiencia del usuario y, por tanto, tratando de enlazar esta experiencia a las "imágenes primordiales o atávicas" de quien transita este espacio diseñado.

Quizá podríamos preguntarnos ¿por qué esta necesidad de mirar hacia el pasado y de acercarse a estructuras de pensamiento mágico religioso relacionadas con el cuerpo? Incluso podríamos pensar que tales estructuras ya están superadas en la inmediatez contemporánea mediante "selfies en Facebook". A continuación, abordaré los conceptos que alimentan esta investigación.

\section{Mito, rito, inconsciente colectivo... definiendo términos de apoyo}

[...] cada individuo cuando inicia su recorrido propio, se encuentra con las marcas dejadas por sus antepasados que le advienen como "arquetipos" o "imágenes primordiales (Mardones, 2000, p.51).
Algunas sociedades con el advenimiento de la revolución industrial, alcanzaron una conciencia diferente del mundo, del devenir del tiempo y su cotidianidad. La invención del artefacto en este proceso se convierte en un problema importante y un aporte para el quehacer del diseño, el cual conlleva el desarrollo de un pensamiento tecnológico y científico avanzado. No obstante, el hombre no se libera en su cotidianidad de los ritos y de algunas estructuras primigenias que subyacen en lo más profundo de su inconsciente. Quizá, por que el ser humano no puede separarse de su naturaleza animal y gremial.

Las ideas de Carl Jung apuntan a que el hombre moderno sigue relacionando sistemas simbólicos y mitos que sobreviven al hombre antiguo, a lo que Freud llama "remanentes arcaicos", presentes, sobre todo, en las imágenes que están en los sueños, en el inconsciente. Algunos de estos símbolos derivan de un modelo significativo común en la humanidad, al que Carl Jung llama "inconsciente colectivo".

Quizá sea necesario en este momento definir otras nociones que actúan como la base conceptual de esta propuesta. Para este proyecto hay dos estructuras componentes muy importantes a desarrollar: el rito y el mito. Un mito es una explicación o relato, una manera de entender la realidad circundante y el universo, o de validar un orden social mediante un hecho relacionado con algún evento natural sorprendente o sobrehumano, en el que media algún personaje con características sagradas que lo diferencian del mundo humano. El mito está vinculado al rito y precede al mito como acción no verbal, posibilitándolo. Un ritual, por tanto, es 
la elaboración continua y repetitiva de un tiempo primordial, en el que se llama a hacer presente el tiempo mítico; es decir, es un acto simbólico que se recrea continuamente. Por tanto, mediante el rito, según Víctor Turner (antropólogo), entramos en comunión con otros, saliendo del tiempo personal e histórico, penetrando en lo trans-histórico.

El mito está relacionado con una realidad simbólica y esta misma realidad está correspondida con la fetichización de un objeto, el cual encarna una realidad propia del pensamiento mágico religioso, en donde el símbolo y la realidad son lo mismo. Un símbolo, según Turner (1967) es una unidad mínima dentro de una estructura ritual. La naturaleza de este no siempre es directa ni clara; por el contrario, es nebulosa y plurisignificativa. El símbolo tiene un nuevo ordenamiento en otra estructura: el mito, mediante este, el inconsciente se revela a la conciencia.

En nuestros pueblos latinoamericanos el mito convive en la vida cotidiana y en la creación continua de símbolos nuevos en la época contemporánea, pero que se remiten a las estructuras anteriores. José Ma. Mardones afirma en su libro el retorno del mito: "Nuestra cultura y sociedad necesitan el mito, precisan conjugar la racionalidad funcional prevalente hoy, [...] Arte, religión, deben estar unidos estrechamente a lo tecno- científico [...]" (2000). Si observamos a nuestro alrededor, podemos constatar que los seres humanos nos rodeamos de objetos o actos vinculados a un ritual.

Si observamos a nuestro alrededor, podemos constatar que los seres humanos nos rodeamos de objetos o actos vinculados a un ritual y hago un paréntesis a manera de dar contexto y validez a esta afirmación. Hace unos pocos días, frente de la catedral de México pude observar a un personaje ataviado con plumas, limpiando con sahumerios a los transeúntes y a los turistas que requieren ser "exorcizados". Todo tipo de personas recurrían a sus servicios.

\section{Figura 1.}

Chamán practicando rito de limpieza a transeúnte. Parte posterior de la Catedral Metropolitana, Ciudad de México (2016).

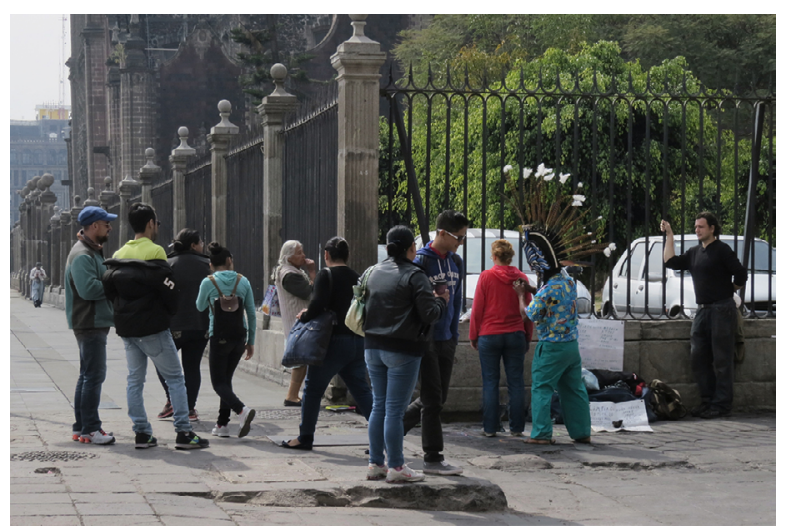

Fuente: Adela Marín

En otra ocasión, a un costado del Palacio de Bellas Artes, un personaje con una carretilla recorre la calle vendiendo objetos de protección y culto con la imagen de "Valverde" un narcotraficante muerto y beatificado popularmente (Fig.2). Con los ejemplos anteriores, se constata que estamos llenos e impregnados de esa doble existencia de la experiencia de lo físico y de lo simbólico, en un pensamiento mágico-religioso de un mundo presente y alterno a nosotros. Existe un realidad concreta, mediada por otra simbólica y mágica.

En otro contexto, en Costa Rica un amigo ateo lleva en su billetera alguna imagen que le fue regalada para tener suerte en los negocios y otro porta unas pequeñísimas flores de color violeta "Santa Lucías", las cuales, 


\section{Figura 2}

Vendedor de estampas y relicarios. Costado del Palacio de Bellas Artes. Ciudad de México (febrero de 2016).

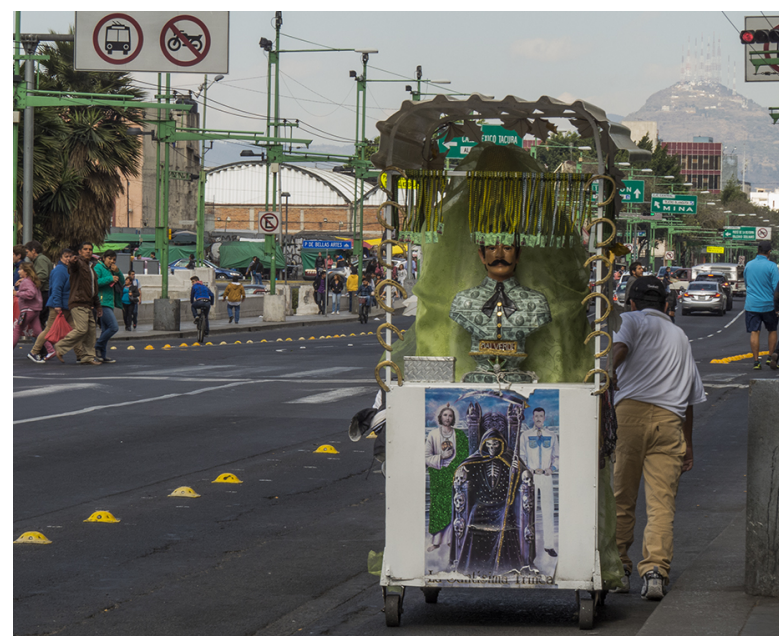

Fuente: Adela Marín

dentro de la tradición costarricense, se usan como amuleto para tener prosperidad en el año. Los ejemplos anteriores ponen en manifiesto cómo en la sociedad contemporánea nos rodeamos de los objetos fetichizados que refieren a un mito o a un rito, y esto sin citar los objetos de producción en serie o de representación de íconos contemporáneos del mass media que también son fetichizados.

El mundo del mito es el mundo del sentido: el ámbito de la búsqueda de respuestas humanas para un ser que tiene la experiencia del desgarro y de vivir en un «mundo roto». Expresar ahí que sea la realidad y la vida [...] huellas en el inconsciente[...] quedaron almacenadas, quizá, como protovivencias, imágenes arquetípicas y como impulsos creadores del alma que irrumpen dramáticamente a través de figuras y modelos en momentos determinados de la vida social y cultural. (Mardones, 2000, p.11)

\section{Figura 3}

Vendedor de artículos de devoción en la festividad de San Judas Tadeo, afueras de la Iglesia de San Hipólito, Ciudad de México (febrero de 2016).

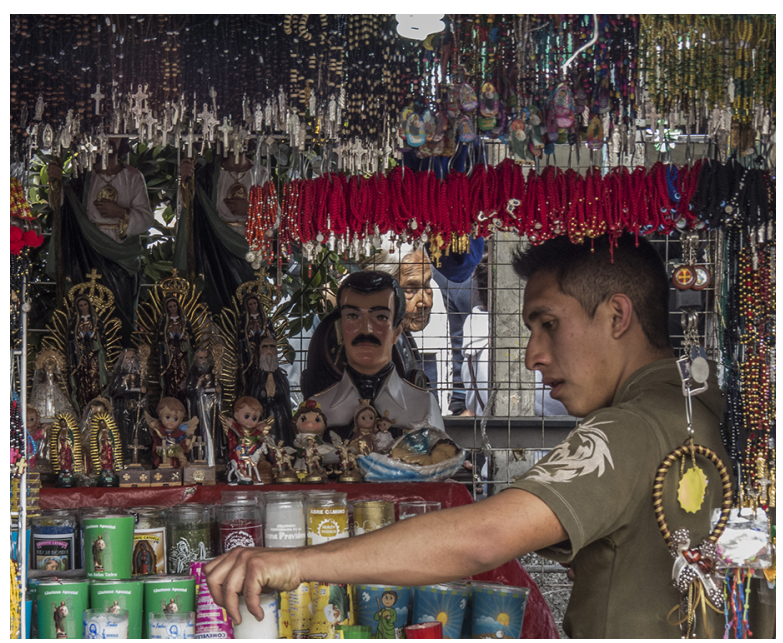

Fuente: Adela Marín

Llevamos en nuestro interior el llamado de ciertos mecanismos de comportamiento animal y, por tanto, como animales, recurrimos a estructuras de poder y gremiales para asegurar la supervivencia y la reproducción de la especie. La percepción y los juicios estéticos que elaboran nuestra manera de mirar el mundo están permeados por estos componentes.

\section{Carl Jung afirma:}

Así como el cuerpo humano representa todo un museo de órganos, cada uno con una larga historia de evolución tras de sí, igualmente es de suponer que la mente esté organizada en forma análoga. No puede ser un producto sin historia como no lo es el cuerpo en el que existe [...] Me refiero al desarrollo biológico, prehistórico e inconsciente de la mente del hombre arcaico, cuya psique estaba aún cercana a la del animal. 
Esa psique inmensamente vieja forma la base de nuestra mente, al igual que gran parte de la estructura de nuestro cuerpo se basa en el modelo anatómico general de los mamíferos.

El ojo experto del anatomista o del biólogo encuentra en nuestro cuerpo muchos rastros de ese modelo originario. El investigador experimentado de la mente de igual modo puede ver las analogías entre las imágenes oníricas del hombre moderno y los productos de la mente primitiva, sus «imágenes colectivas» $y$ sus motivos mitológicos. (1964, p. 67)

Franklin Hernández (1998) en su libro Estética Artificial declara que un juicio estético puede provenir de lo consciente y lo inconsciente y que la supervivencia es la razón de todos los juicios estéticos, traduciéndose en tres instintos básicos: la supervivencia, la reproducción sexual y la jerarquía humana.

En su libro se refiere a que la percepción está mediada por bancos de datos o patrones de reconocimiento estético de carácter genético, junto a otros que provienen de experiencias aprendidas culturalmente. Dichos bancos son llamados "bibliotecas asociativas" y están formados por recuerdos y sistemas de comparación de los complejos cerebrales límbico y reptílico; el primero establece aspectos de carácter emotivo y clánicos y, el segundo, atributos rituales y jerárquicos. Esto podría tener mucha relación con las teorías del inconsciente colectivo, planteadas por la psicología profunda de Jung, donde se estructuran "imágenes primordiales".

Siendo este un ámbito donde las necesidades básicas son reelaboradas, mediante una estructura simbólica en el inconsciente, Jung afirma que el símbolo es la máquina psíquica que transforma energía del inconsciente colectivo al consciente. Por tanto, para este autor, el símbolo es un lenguaje que media entre situaciones y sentidos inconciliables desde el punto de vista racional: el pasado, la muerte y la vida, lo inmanente, entre otros.

Más allá de la racionalidad funcional, la estandarización y la producción en serie contemporánea, hay una estructuración mítica en lo inmanente de la supervivencia del hombre. Por tanto, mi proyecto artístico utilizó las conexiones de objeto mítico- simbólico fetichizado, el cual busca establecer un lazo entre la ritualidad y los primeros objetos diseñados, tales como la Venus de Willemdorf, los recipientes rituales y la caverna con intervención pictográfica.

\section{Figura 4}

Venta de imágenes festividad de San Judas Tadeo, afueras de la Iglesia de San Hipólito, Ciudad de México (febrero de 2016).

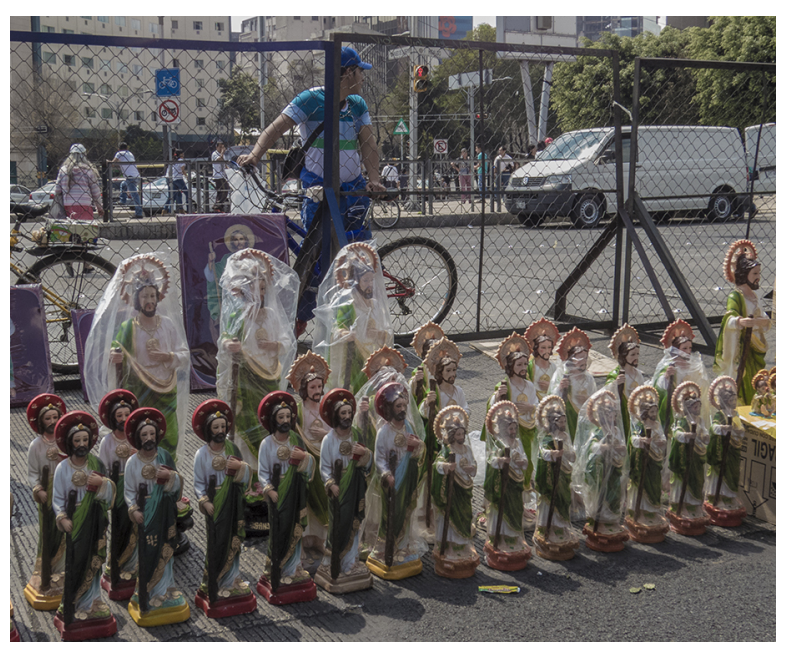

Fuente: Adela Marín 


\section{Artículos}

Dentro de estos objetos diseñados también podemos contar con los espacios de carácter ritual (que posibilitan una experiencia particular que se sale de la cotidianidad del presente para entrar en "el tiempo trans-histórico") coincidentes en las diferentes zonas geográficas del mundo. Derivado de esta premisa, en mi instalación artística, se utilizaron como referentes los sitios de meditación como el templo, el lugar para ceremonia del té, entre otros. Estos sitios permiten una sensación de resguardo, una especie de útero protector (estableciendo una interesante relación con la supervivencia), que podría ligarse al concepto del "paradigma de la tranquilidad", del cual parto para desarrollar el diseño del espacio instalativo. En este sentido, de acuerdo con Hernández "[...]el estado de tranquilidad se genera cuando el análisis del contexto da como conclusión la ausencia de peligro, correspondiente a los parámetros esperados en las bibliotecas asociativas" (1998).

Por otro lado, las sensaciones que se trabajaron en el proyecto partieron de ordenamientos de ritos y símbolos, mediante los elementos cosmogónicos que detallaré más adelante, junto con la clasificación del imaginario que establece Gilbert Durand, constituida en dos regímenes: el diurno y el nocturno. Este último régimen miniaturiza el peligro y establece el abismo en el vientre y lo femenino como copa receptora de sustancias nutritivas. Asimismo, abarca el sueño arquetípico del regreso al útero -al estado prenatal- fuera del tiempo y del espacio (paradigma de la tranquilidad mencionado por Hernández). Lo anterior, aunado a los amplios estudios de
Mircea Eliade relacionados con los mitos que conforman un banco de datos simbólicos de diversos orígenes y latitudes geográficas, será abordado en el apartado de relaciones simbólicas: elementos y culturas.

\section{Configuración de una propuesta}

Se desarrolló, entonces, una instalación artística a partir de todo este bagaje conceptual y de los acercamientos investigativos a las representaciones de lo divino y de lo sagrado en diferentes sistemas religiosos. Es importante entender que estas representaciones son llevadas a la acción por los ritos en diferentes culturas, las cuales normalmente son ordenadas y entendidas dentro de las polaridades de vida, de la muerte y de lo masculino-femenino. Por otra parte, dichas polaridades tienen elementos cosmogónicos correspondientes de manera casi universal, siendo la polaridad de la vida relacionada con la tierra y el agua, elementos generalmente representados en deidades femeninas (sin ser la regla absoluta) y la polaridad de la muerte, los elementos vinculados con el aire y el fuego, generalmente masculinos, en sus representaciones (con excepciones). Asimismo, la necesidad de celebrar la fertilidad está presente en todas las culturas y se encuentra unida a rituales; en el caso de los ritos femeninos, estos establecen una relación con la luna y los períodos menstruales, las mareas y la serpiente (de doble simbología, pues tiene un gran contenido fálico también). 
Se elaboró, con lo anterior, contrastaciones entre representaciones y ritos. Algunos de estos sobre el cuerpo o elementos representativos y gráficos relacionados con temas cercanos a este, tales como el círculo, los mandalas, la esvástica, la luna, el parto, el mundo, el yoni, entre otros.

El proceso de configuración y recolección de datos se concentró en un ordenamiento de elementos simbólicos que apelan a los sistemas reptílico y límbico del cerebro, tomando en cuenta las necesidades básicas humanas, los cuales construyen sentidos mediante las bibliotecas asociativas, al hurgar en imaginarios recurrentes de los diversos sistemas simbólicos que pudieran constituir una conexión con el inconsciente colectivo. Para lo anterior, se toma en cuenta la información de Mircea Eliade, Carl Jung, Gilbert Durand, estudios sobre diosas, otros estudios antropológicos comparados y mitologías sobre rituales de fertilidad femeninos desde la perspectiva de la vida o la muerte.

\section{Recapitulando en la creación de la pieza}

Se decodificó un recorrido a partir del principio del eterno retorno, debido a que la instalación estaba vinculada con la experiencia cíclica del cuerpo y la vida, en un tiempo circular. Partiendo del símbolo del uróboros -la serpiente que se muerde la cola-, en relación con el concepto del principio y el fin. Dicho símbolo es coincidente en una gran cantidad de culturas; asimismo, la serpiente es asocia$\mathrm{da}$, de forma frecuente, con mitos primordiales de la creación, coligada a lo femenino, al cambio, la luna, la menstruación, o la pareja primordial (ejemplo de ello, es la figura de Adán y Eva). De hecho, Mircea Eliade en su libro Patterns in Comparative Religion, sostiene que el animal-lunar por excelencia es la serpiente, dado que cambia su piel y se transforma como la luna y la cérvix femenina. Además, en este recorrido, se partió de un elemento unificador y configurador del espacio: la espiral, la cual es un referente simbólico de los ciclos, las fases lunares y su influencia sobre las aguas y la fecundidad.

A partir de esta configuración de una pasaje con pequeñas estaciones constituidas en zonas rituales, relacionadas con cada período vital del cuerpo, se construye un espacio que trata de comunicar la sensación que puede transmitir un lugar de contemplación, a propósito del paradigma de la tranquilidad. Asimismo, se utilizó el color blanco para todo el interior de dicho espacio, como referente lunar y el recurso de tela para delimitar estos espacios, como un material cercano históricamente a lo femenino. También se contempló que cada aposento fuera interpretado por un elemento cosmogónico, este vinculado a una lógica ritual cercana al fenómeno vital que se estuviera trabajando.

Se incorporó, de igual manera, la presencia real de estos elementos cosmogónicos en cada cubículo. Se colocó agua, tierra, fuego y aire; este último se hizo visible mediante humo (en el espacio en el que le correspondió). Pudo haberse utilizado la imagen fotográfica para representarlos, sin embargo, se dispuso ponerlos naturalmente para reforzar el carácter ritual de la pieza. Se utilizaron 


\section{Artículos}

también, a lo largo de los módulos, diferentes recipientes de cerámica (por su constitución de tierra), los cuales se ubicaron en el piso para reforzar el carácter de la polaridad femenina de este elemento cosmogónico. El uso de los receptáculos tenían estrecha relación con el ámbito de especialización de mi maestría (diseño del espacio, la imagen y el producto) por la apropiación de objetos fabricados en serie. Ellos fueron re-semantizados o fetichizados, en una búsqueda retórica, para aprovechar su forma y color, en relación con el sentido comunicativo o representativo que necesitaba el espacio en cuestión y esta pieza artística en general.

En el interior de la instalación se trataron los siguientes espacios:

-El inicio y el nacimiento

-La menstruación

- La gestación

-El climaterio

-La vejez

-La muerte

Seguidamente, incluyo una ubicación contextual de algunos de los estudios que dieron cuerpo al sistema simbólico diseñado.

\section{Figura 5}

Diferentes recipientes utilizados en la instalación.
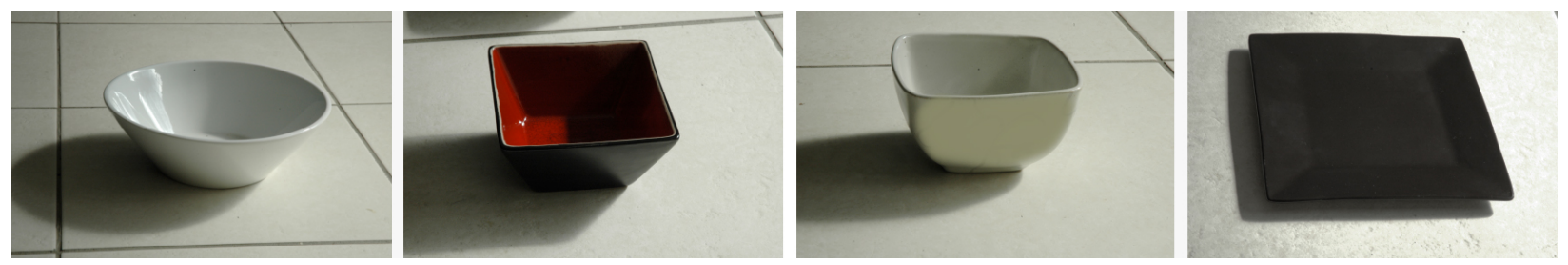

Fuente: Adela Marín 
Artículos

Figura 6

Plano recorrido y disposición de elementos en la instalación

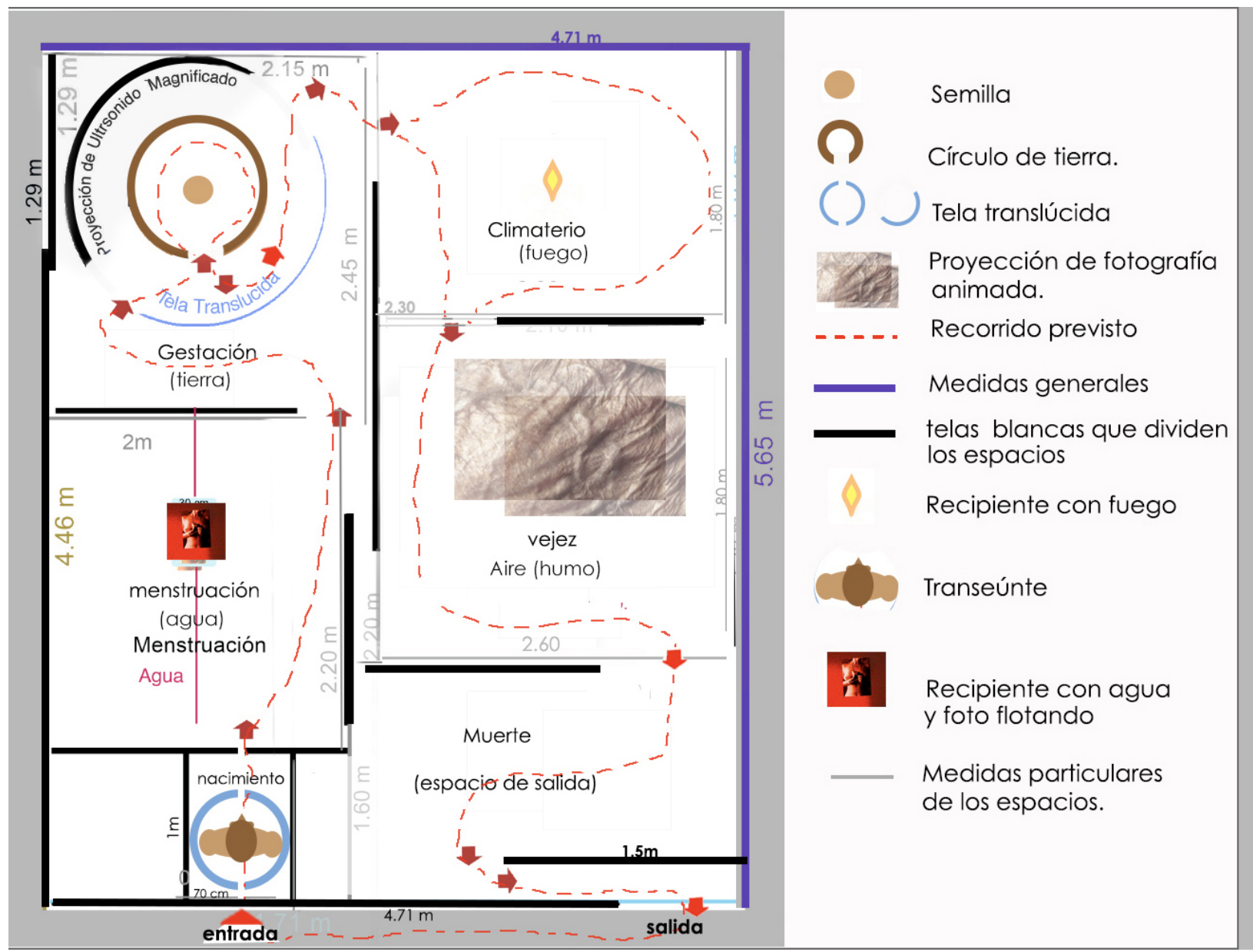

Fuente: Adela Marín

\section{La serpiente cambiante, el caracol y la luna}

Por ser la luna un astro que crece y disminuye, es asociado al cambio, lo cíclico, la vida que se repite rítmicamente, al nacimiento, la fertilidad y la muerte. Así, tanto la espiral, como el caracol son relacionados con esta simbología de lo femenino, estableciéndose una analogía vulva-concha. El caracol, al igual que la luna, se esconde, "se convierte en el lugar de la teofanía lunar, como en la antigua religión mexicana, en la que el dios de la luna, Tecciztécatl, se representa encerrado en una concha de caracol [...]". (Eliade, 2005, p. 153) 


\section{Artículos}

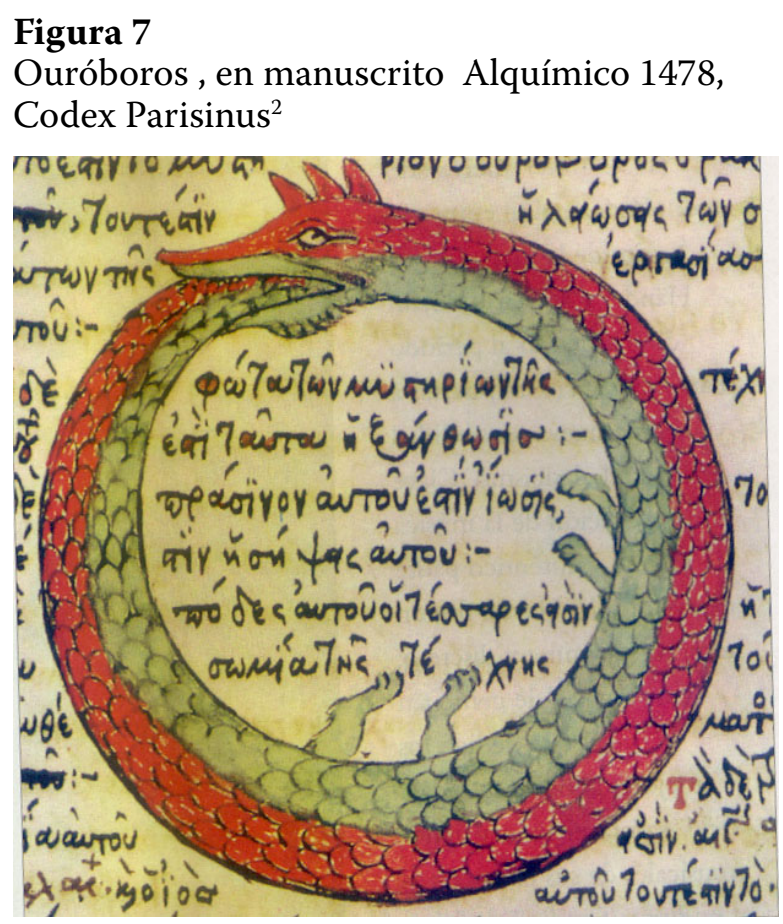

Fuente: Adela Marín

Asociado con con la cita anterior, el elemento configurador del recorrido fue la espiral y sus relaciones con la luna, como ya se anotó.

De igual forma, la serpiente, por tener la capacidad de regenerar y transformarse, posee una fuerza inmortal; es decir, una fuerza lunar. Los papúes consideran la menstruación como un lazo con la luna, por lo cual elaboran esculturas en madera con reptiles que salen de las partes genitales de las mujeres; asimismo, en una gran cantidad de civilizaciones neolíticas asiáticas y aborígenes americanas, se representa a la serpiente decorada con rombos. Esta figura geométrica es conectada con la vulva femenina. La tribu india de los komati (provincia de Mysore) conjura la fecundidad de las mujeres por medio de serpientes de piedra. En India, las mujeres que desean a un niño adoran a una cobra. De igual forma, la serpiente y la mujer han sido relacionadas con el agua, manantiales y lluvias, tanto en creencias europeas como indígenas e indias. Como ejemplo de lo anterior es posible citar a Tláloc, Sébillot en Francia y el rito sarpabali (serpiente- luna- lluvia) (Eliade, 2005).

Es importante mencionar que en la instalación se ubicó el símbolo del uróboros en la entrada. Esta serpiente no solo es relacionada con lo cíclico femenino, sino que también simboliza el descenso de lo espiritual a lo físico y viceversa; de hecho, en la alquimia significó la transmutación de la materia (Bercker, 1997, p. 328), lo cual coincide nuevamente con el cambio lunar femenino, al tránsito corporal de crecimiento y fecundidad hasta la muerte, representado en los diferentes espacios de este proyecto.

\section{La luna y el agua}

[...] El «espíritu primitivo» habiendo descubierto las virtudes de la luna, establece relaciones de simpatía o de equivalencia entre esas series de fenómenos. Así por ejemplo desde tiempos muy antiguos,

${ }^{2}$ Copia por Theodoros Pelecanos de Creta en 1478, de un manuscrito perdido de un tracto altomedieval que se atribuyó a Synosius de Cirene (d. 412). 
Artículos

en todo caso desde la época neolítica, al mismo tiempo que el descubrimiento de la agricultura, el mismo simbolismo une entre ellos a la luna , las aguas, la lluvia, la fecundidad de las mujeres, la de los animales, la vegetación, el destino del hombre después de la muerte y las ceremonias de iniciación. [...] Si existen series de comentarios rituales o míticos laterales, desprendidos de una función bien determinada, y en cierto modo especializada, de la luna. (Eliade, 2005, p. 151)

Los ritos desarrollados en una gran cantidad de pueblos se encuentran vinculados con la renovación, el volver a lo pre-formal, a un nuevo nacimiento; la inmersión en las aguas o baño sagrado es practicado en el culto a grandes diosas de la fecundidad y se vincula también en la agricultura, con la buena cosecha, la proliferación de bienes y también a rituales mágicos iniciáticos de purificación ${ }^{3}$.

En el cristianismo este símbolo es muy frecuente en la frase "Agua viva" utilizada en la ceremonia del bautizo y en el uso del simbolismo del pez, con lo cual se recurre nuevamente a arquetipos universales. En relación con esta ceremonia, un ejemplo de vinculación son las lustraciones bautismales de los recién nacidos en México, los cuales son consagrados al dios del agua Chalchihuitlicue, Chalchiuhtlatónac, su verdadera madre ${ }^{4}$.

Los elementos agua-luna-mujer en la prehistoria era relacionados con la fecundidad. Inicialmente en la prehistoria y en Egipto el agua fue representada con el signo VVV. «En las mitologías amerindias el signoglífico del agua, representado por un recipiente lleno de agua siempre asociado a emblemas lunares (cf. Reproducción de Sahagún del Códice Nuttal, etc., en el Vol. de Leo Wiener Mayan and Mexican Origins, Cambridge, 1926, pp.49 ss., 84 ss.) La espiral, el caracol (emblema lunar), la mujer, el agua, el pescado, pertenecen constitucionalmente al mismo simbolismo de fecundidad, verificable en todos los planos cósmicos». (Eliade, 2005, p. 179)

En el paleolítico la espiral simbolizaba la fertilidad acuática de la luna, por lo cual, el desarrollo de la propuesta tomó en cuenta este aspecto. Algunos de los recipientes en la instalación fueron rodeados de agua, como un recurso alusivo a los fluidos del cuerpo. El recipiente fue una metáfora del cáliz o copa, figuras vinculadas con la abundancia.

En la India la copa representa el pecho materno; congruente con la media luna, en los rituales es relacionado con el elixir de vida y el útero. En el cristianismo el cáliz es relacionado con la Virgen María (Bercker, 1997, p. 62, p.330), un arquetipo de la madre.

Todos los emblemas del agua, están inmersos en las fuerzas sagradas del abismo, controlando la fecundidad del mundo, una fuerte referencia al régimen nocturno presente en las teorías de Gilbert Durand.

\footnotetext{
${ }^{3}$ Ver pág. 184. Mismo libro.

${ }^{4}$ Ver pág. 181. Mismo libro.
} 


\section{La luna y los ritos de sangre en la pola- ridad femenina}

Algunos sistemas míticos se construyen aludiendo a que la mujer primordial copula con la serpiente y de esto resulta la menstruación. Yadira Calvo en su libro Éxtasis y ortigas (2004) menciona a la demonio femenina persa Jahi, cuyo nombre significa menstruación. Este mito antecede al de los judíos y pudo dar origen al mito de Eva. Jahi, la prostituta, copula con Ahriman, la Gran Serpiente; esta sedujo al primer hombre. Lilith y Jahi han sido asociadas con perjuicios a la humanidad, lo cual coincide con el surgimiento de sistemas patriarcales en el Neolítico, donde se establece un dominio masculino y la anulación de la importancia de las representaciones femeninas; estas son suprimidas o transformadas en divinidades secundarias, dependientes de dioses machos.

Sin embargo, algunos investigadores como Campbell y Newman, gracias a rastros arqueológicos, afirman que los sistemas religiosos predominantes en algunos pueblos del Neolítico y Paleolítico no siempre fueron conformadas por dioses masculinos, sino más bien por la religión más antigua de la humanidad: el culto a la Gran Diosa.

Calvo cita a Campbell «El Tiempo y La Materia, en cuyo límite todos los seres surgen y mueren[...]» y más adelante afirma «Se trataba, a todas luces de una religión de los menstruos, los misterios del nacimiento y las fases de la luna. La sexualidad femenina constituiría el eje central de la comunidad humana; las mujeres habrían sido las promotoras del primer movimiento espiritual de la humanidad: el culto a la Gran Madre». (2004, cap.1)

Por otro lado:

La luna es el instrumento de medida universal. Toda la terminología relativa a la luna en las lenguas indoeuropeas deriva de esta raíz: mas (sánscrito), mah (aveestico), mah (antiguo prusiano), menu (lituano), mena (gótico), mene (griego), mensis (latin). [...]El tiempo controlado y medido por medio de las fases de la luna es, decíamos, un tiempo «vivo». Se refiere siempre a una realidad biocósmica, la lluvia o las mareas, la siembra o el ciclo menstrual. Bajo la influencia o según el ritmo lunar se coordinan de una serie de fenómenos de los «planos cósmicos» más diversos. (Eliade, 2005, p.151)

\section{La tierra y la madre}

Cada uno de los elementos mencionados se entrelaza en diferentes simbologías que tienen una misma raíz. La correspondencia tierra-luna es popularizada por el descubrimiento de la agricultura; esta síntesis luna-tierra-madre se relaciona con las ambivalencias bien-mal, muerte y fertilidad y destino (Husain, 2001, p.29).

En cuanto a atributo de la Gran Diosa, la serpiente conserva su carácter lunar (de regeneración cíclica) unido al carácter telúrico. En un momento dado, la luna es identificada con la tierra, considerada a su vez como la matriz de todas las formas vivas (Eliade, 2005, p. 86). 
A su vez, algunas diosas participan tanto del carácter sagrado de la luna, como el del sol; estas son al mismo tiempo divinidades funerarias (los muertos se van bajo tierra o a la luna, a fin de regenerarse y reaparecer bajo una forma nueva). La serpiente también es un animal funerario que, por su elemento de regeneración, puede estar presente en las ceremonias de iniciación ${ }^{5}$.

La Pachamama en Perú, diosa de la tierra, presenta aspectos benignos que suelen relacionarse con los de la Virgen María, por lo cual se denomina también como Santa Tierra. Además presenta aspectos negativos vinculados con la destrucción y la muerte. (Husain, 2001, p. 29).

Una de las primeras teofanías de la tierra en cuanto tal, especialmente en cuanto capa telúrica y profundidad tectoniana, fue su «maternidad», su inagotable capacidad de dar fruto. Antes de ser considerada como una diosa-madre, como una divinidad de la fertilidad, la tierra se impuso directamente como madre, tellus mater. La evolución ulterior de los cultos agrícolas...» «Dieterich empieza su estudio recordando tres costumbres usadas en la antigüedad-deposición de un niño recién nacido sobre la tierra, inhumación de los niños (en contraste con la incineración de los adultos), posición a ras de tierra de los enfermos y de los agonizantes- para reconstruir la figura de la arcaica diosa-tierra, de la «tierra-madre-de-todo» (panmétôr Gê) [...] la de la tierra considerada como fuente al mismo tiempo de fuerza, de «alma», de fecundidad, la de la «tierra-madre». El parto sobre la tierra (humipositio) es una costumbre muy frecuente en muchos pueblos; entre los guriones del Cáucaso, así como en algunas regiones de China, las mujeres se echan al suelo en cuanto les llegan los dolores del parto, a fin de partir directamente sobre la tierra [...] (Eliade, 2005, pp. 226-228).

Esta analogía con el parto fue sorprendente, pues uno de los espacios en que se utilizó el elemento tierra fue el de la gestación, por el poder creador que encierra su simbolismo; la tierra unida al símbolo del círculo y al centro como ombligo. En el cristianismo el círculo ha sido asociado a las diferentes etapas de la creación. Para Jung el círculo es el símbolo del alma y del yo.

[...] En diversas tradiciones vemos a la creación partir de un "centro», porque allí se encuentra la fuente de toda realidad y por lo tanto de la energía de la vida. Sucede incluso que las tradiciones cosmológicas expresen el simbolismo del centro en términos que parecerían tomados de la embriología: «El santísimo creo el mundo como un embrión. Así como el embrión crece a partir del ombligo, del mismo modo Dios comenzó a crear el mundo por el ombligo y de allí se extendió en todas las direcciones» (Textos citados por Wensinck, p.19) (Eliade, 2005, p.338)

\footnotetext{
${ }^{5}$ Ver pág. 16, mismo libro.
} 


\section{Artículos}

El espacio de la gestación se generó a partir de un centro con una semilla y un círculo de tierra; la descripción detallada se elaborará en el estudio de los cubículos diseñados que viene a continuación.

\section{Estudio de cada espacio correspondiente a un período vital}

\section{La entrada y espacio inicial}

Se establecieron relaciones simbólicas con el inicio, la vagina, el nacimiento y la bolsa embrionaria. Esta parte constituyó la entrada a toda la instalación, involucrando una experiencia que se proponía comunicar translucidez, penetración y a la vez salida. La entrada principal estuvo dispuesta en forma vaginal y en su parte exterior tenía impresa un uróboros. Esta era la primera imagen que recibía a quien iniciaba el recorrido. El primer espacio a penetrar se configuró de una forma estrecha y ojival, para que el transeúnte sintiera cierta incomodidad que lo remitiera al nacimiento. Ya en el interior, se esperaba crear una sensación de estrechez y transparencia, dando la similitud con una bolsa embrionaria, para evocar sensaciones y reminiscencias primarias de supervivencia.

Se usó una luz cenital de coloración roji$\mathrm{za}$, para que el ambiente fuera envolvente y consecuente con una experiencia orgánica humana. El participante del espacio, una vez adentro, estaba rodeado de un pequeño sitio de aproximadamente $70 \mathrm{~cm}$ de ancho por un

\section{Figura. 8.}

De izquierda a derecha: A. entrada al espacio general, B. entrando en el espacio del nacimiento ${ }^{6}, \mathrm{C}$. vista de adentro hacia fuera, abertura de salida del nacimiento hacia la entrada.
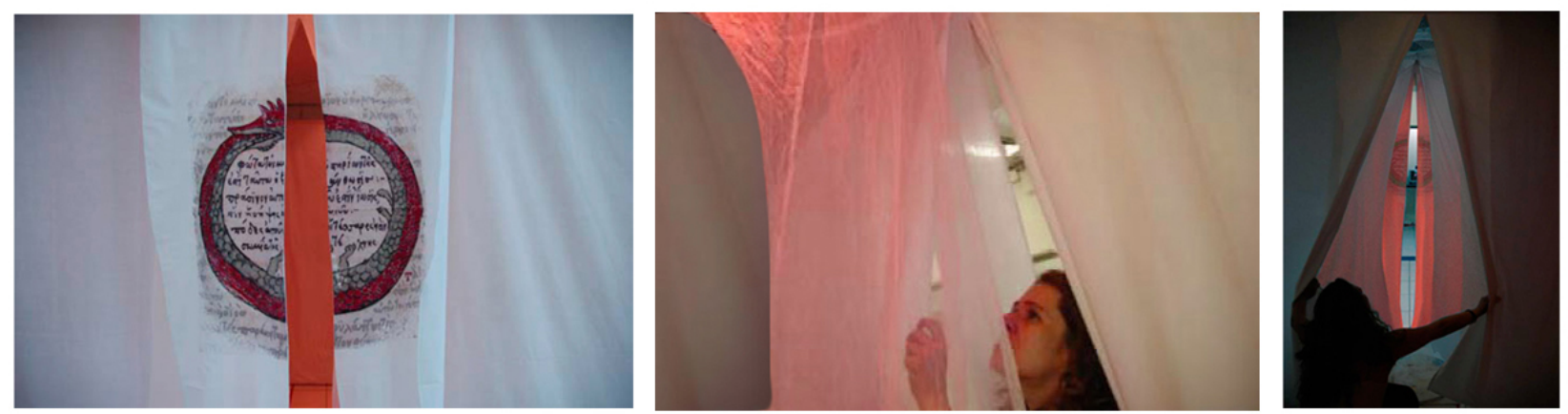

Fuente: Adela Marín

${ }^{6}$ Pueden verse las dimensiones de la tela translúcida y elástica, que constituyen la bolsa embrional (correspondiente al cilindro cálido en la foto), además de este, el cubículo se encuentra recubierto por otras telas laterales más densas que delimitan el espacio, de manera que la persona que entra no puede ver ningún otro lugar, se encuentra en un sitio reducido (en la fotografía faltan estas telas). 
Figura. 9

Torso para el espacio de la menstruación.

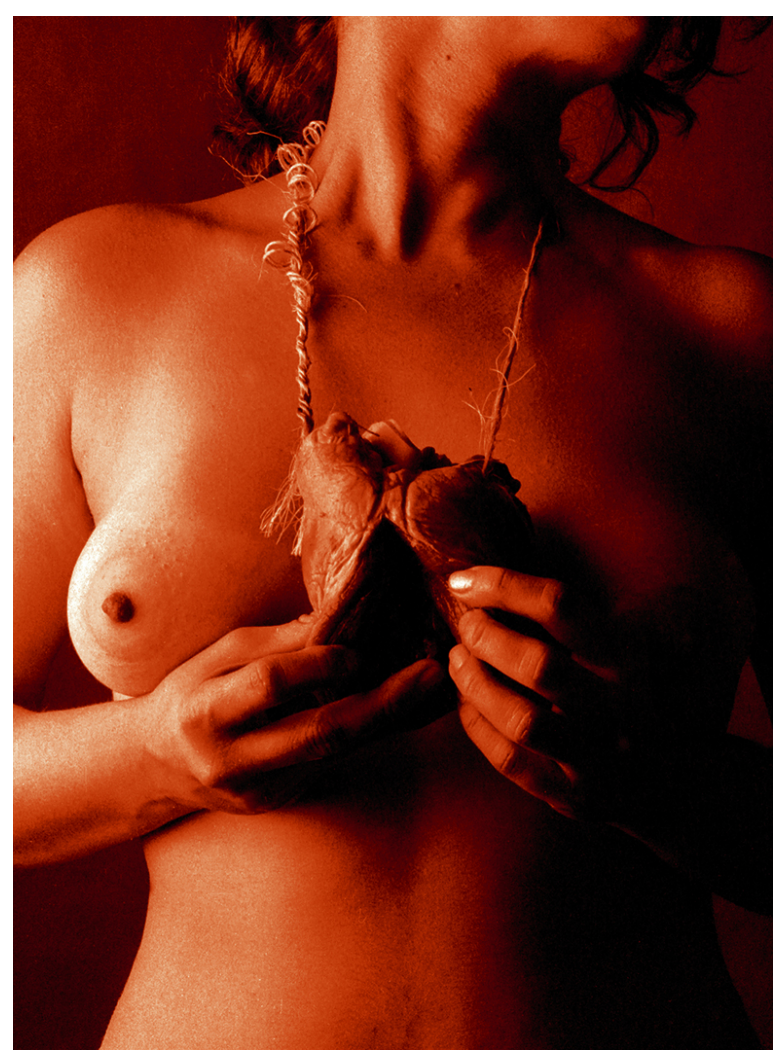

Fuente: Adela Marín

metro de largo, recubierto de una tela transparente y elástica que contenía o rodeaba su cuerpo de un forma ajustada, para luego pasar al siguiente espacio: la menstruación.

\section{La menstruación}

En este caso, se establecieron relaciones alegóricas con la copa (el grial), el recipiente, el útero, la fecundidad, la luna, la serpiente, el dolor, la sangre y las mareas.
Asimismo, se utilizó el elemento agua y el corazón como metáfora de dolor. Se instaló una fotografía flotando en este líquido (fig. 10). La imagen seleccionada fue parte de otra obra desarrollada anteriormente (pero en miniatura), la cual tenía el tamaño aproximado de una fotografía pasaporte. Esta consistió en un torso femenino rojo con un corazón de carne real totalmente abierto, que rememoraba, en su forma, a unos labios vaginales (Fig.9).

Me parece pertinente la relación simbólica y metafórica que pueda establecerse, a su vez, con las vírgenes dolorosas barrocas. En este sentido, la menstruación es la finalización de un período reproductivo, y su limpieza representa la imposibilidad de ser madre en esa ovulación particular; por tanto, conjuga una polaridad de muerte y vida en un sólo momento, quizá una pérdida. Esta imagen podría ser una forma metafórica de madre dolorosa sin presencia de hijo. El simbolismo de la serpiente, que muta y se renueva, se sintetizó en una línea roja que atravesaba toda esta sala.

\section{Figura 10}

Elementos de la menstruación (detalles)

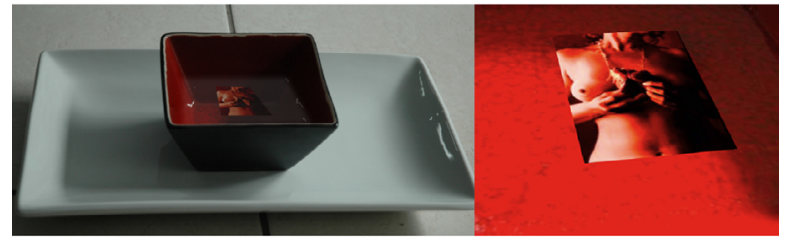

Fuente: Adela Marín 
Artículos

\section{Figura 11}

Espacio de la gestación y detalles.
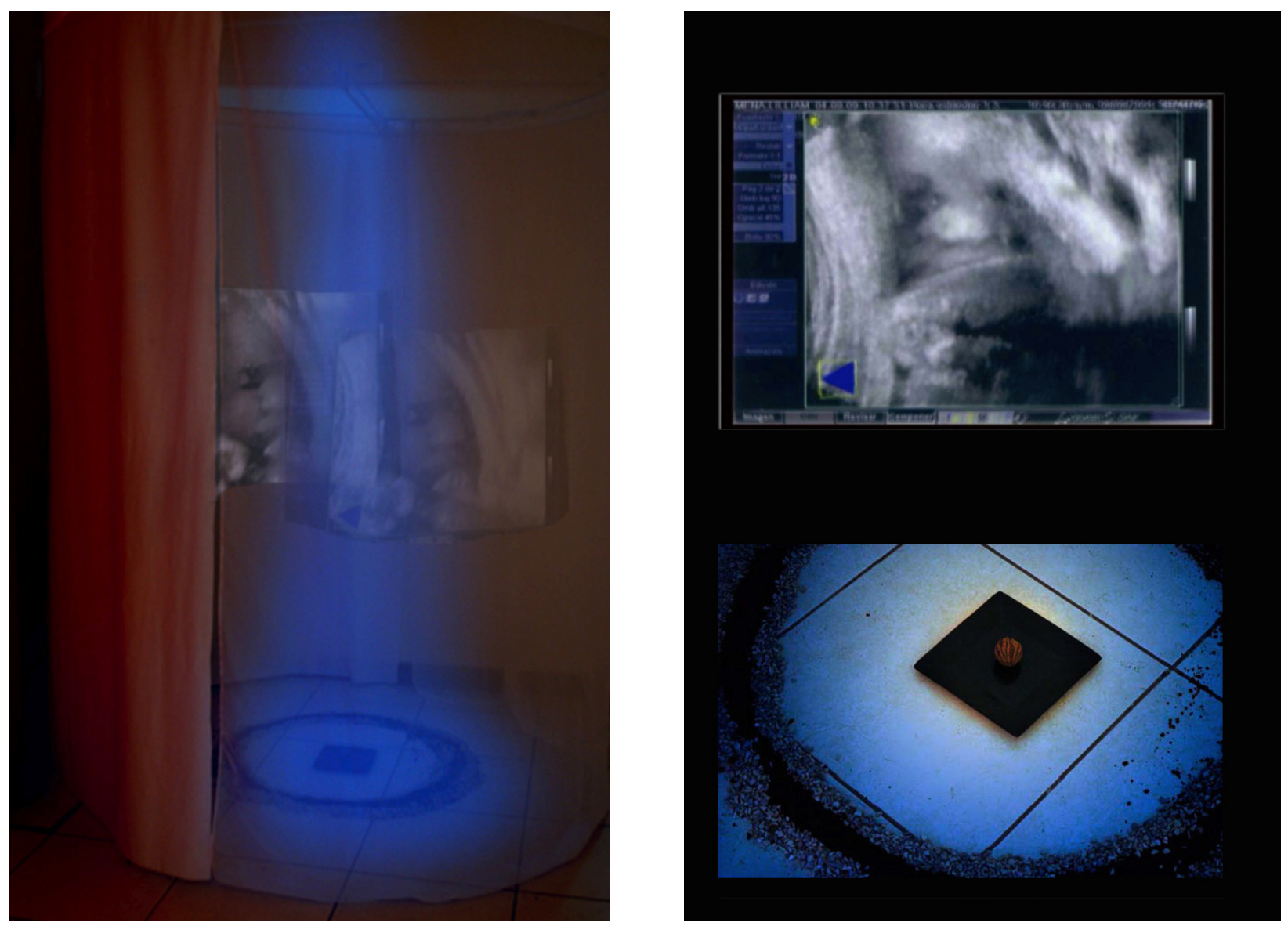

Fuente: Adela Marín

\section{La gestación}

Se establecieron relaciones simbólicas con la bolsa embrionaria, el círculo, la semilla, el centro, el ombligo y el útero. El elemento cosmogónico asociado fue la tierra, el cual está vinculado con la polaridad de la vida en una gran cantidad de culturas. Por otra parte, el círculo también es una figura de gran potencia significativa, relacionado con

la autoafirmación, la creación, el génesis, la tierra paridora y germinadora. Se ejecutó en el montaje un área redonda y translúcida, un gran útero, un lugar de espera a diferencia de la zona del nacimiento, que se concibiera como un sitio de tránsito. Este fue un espacio detenido, que se atravesaba pausadamente en forma circular, siendo esta la única manera en que se podría transitar, debido a 
su colocación y a la delimitación cuidadosa que se estableció. Se colocó, asimismo, un círculo de tierra y en el centro una semilla en un plato de color terroso. Bordeando estos elementos se instaló una tela transparente. Sobre esta tela, se proyectó la animación de un ultrasonido obstétrico con un ser en gestación, que se complementó con el sonido de un corazón. La proyección del feto provocó una sensación de ingravidez sobre la tela transparente (otra bolsa embrionaria). El espacio se coloreó de una luz azul puntiforme para remitir a los regímenes nocturnos que menciona Gilbert Durand.

\section{El climaterio}

El climaterio es un período de tránsito y cambio en la mujer, donde el ciclo reproductivo se detiene, concretándose en la menopausia. El elemento cosmogónico del fuego fue relacionado con este período, por su potencial de transformación y por ser contenedor de representaciones vinculadas con la muerte.
Figura 12

Zona del climaterio

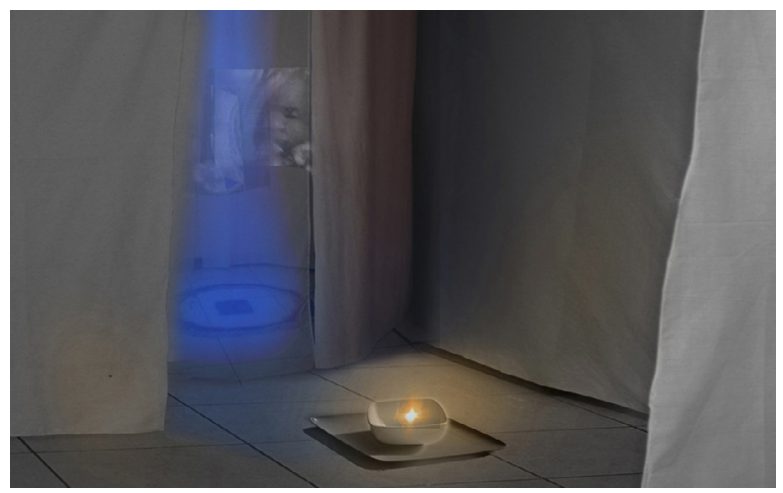

Fuente: Adela Marín

Asimismo, la menopausia es muy raramente representada en los ritos de paso en las culturas ${ }^{7}$. Dada esta característica de su escasa iconografía, es que se optó por una resolución minimalista, con la única presencia de un recipiente blanco añejo y un pequeño contenedor de agua con fuego flotando (elemento cosmogónico de muerte) en su superficie. Con lo anterior se establece, entonces, un planteamiento diferente a la menstruación, que fue configurado en un recipiente rojo.

${ }^{7}$ En raras ocasiones existen ritos de paso en la llegada de la menopausia, en contraste de la abundancia de estos asociados a la menstruación, en algunas sociedades se relaciona la menopausia como entrada a la edad de respeto de las mujeres mayores, siendo la mujer postmenopáusica capaz de guiar, proteger a su descendencia y hacer labores de médicas. Sin embargo, Cabello cita que únicamente ha encontrado un rito de paso cercano a la menopausia, asociado a ritos de la muerte en Papúa-Nueva Guinea, donde la mujer está en contacto con los espíritus, convirtiéndose en una especie de médium, intermediaria entre los mundos masculino y femenino. Esto ilustra bastante la asociación de la mujer mayor con la muerte. Según Cabello, Turner (1988) afirma que la mujer se encuentra en una situación de liminalidad que se caracteriza por la ambigüedad, pudiendo ser esta situación asociada a las terribles divinidades mexicanas de la fertilidad y la muerte (Cabellos, 1995, pp.134-136).

Este aspecto refuerza que en el espacio de la instalación dedicado a la menstruación, tenga como elemento cosmogónico el fuego (asociado a la muerte, también en algunas culturas a la sabiduría y la guía). 


\section{Artículos}

Figura 13

Espacio de la vejez

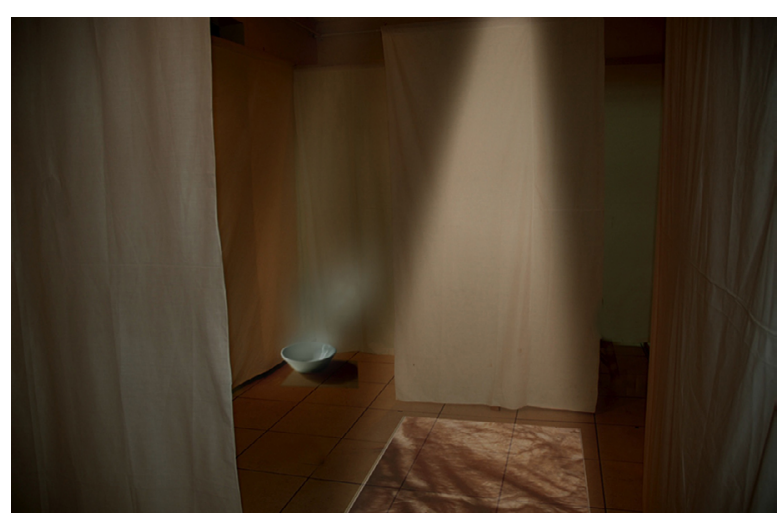

Fuente: Adela Marín

\section{La vejez}

Igual que la serpiente que cambia de piel, el cuerpo muta y se acerca al final de la vida o a un nuevo inicio. La polaridad de la muerte es tratada, en este recinto, con el elemento cosmogónico del aire, mediante la incorporación de humo. Para lo anterior, se utilizó la proyección de una imagen fotográfica consistente en un detalle macro de la piel de una anciana. Se hizo una animación de este detalle del cuerpo magnificado en cuanto a cercanía, proyectándose en el piso, de manera que pareciera movimiento de agua, mediante la textura de su piel.

\section{La muerte}

Se decidió representar esta zona mediante el vacío. Se concibió este lugar como un espacio de tránsito. Rompiendo con las referencias rituales, para optar por la ausencia. La única presencia objetual fue un recipiente blanco que dispensaba humo. Este sitio precedió a la salida, planteando un nuevo comienzo del recorrido que evoca al mito del eterno retorno. La salida estaba junto a la puerta de inicio del recorrido.

\section{Conclusiones}

El hecho de incorporar una reflexión sobre el proyecto La Ruta de la Luna, en este artículo, es una manera de dar constancia o memoria de un proceso de investigación de trabajo con las respectivas disciplinas que se articulan para nutrirlo. Debo aclarar que mis aproximaciones a la teoría no son especializadas y que los ámbitos teóricos a los que se recurrió fueron abordados como una referencia para la creación. También es importante anotar que hubo otros contenidos que no fueron incluidos dentro de los campos disciplinares que componían el proceso. De forma principal, se obviaron meditaciones sobre el ámbito del diseño y valoraciones técnicas sobre los resultados del proyecto que, en el contexto de esta revista, no son necesarias.

Ahora bien, en un proyecto de esta naturaleza, podría resaltarse el proceso de construcción de la obra, que escapa a la materialidad de la misma y que se enlaza, sobre todo, con la compilación de conocimiento, memoria y construcción de significado en la investigación artística, junto con las interrogantes globales que podrían plantearse acerca de la memoria arcaica e instintos básicos de supervivencia, de los cuales no puede negarse su presencia, dada 
la conformación cerebral, con sus distintas capas evolutivas, que hace del cuerpo un contenedor de una historia personal, social, universal y trastemporal, más allá de la conciencia. Por tanto, esta información es un material valioso de análisis para la creación.

Este proyecto plantea la aventura perceptual de estar inserto en la experiencia ritual de un cuerpo femenino. Dado el tema, podría establecerse un diálogo de esta pieza con obras antecesoras de algunas mujeres precursoras del arte feminista, como es el caso de Shigeko Kubota con su obra Vagina Painting, la cual evoca en su performance la representación de sangre menstrual a partir de pintura roja sobre un espacio blanco, esta aplicada con los movimientos de su pelvis. De igual forma, las instalaciones, fotografías, dibujos y collage de Mary Beth Edelson, de forma específica con su proyecto Goddess Head en donde escudriña en los símbolos arcaicos del matriarcado; también, algunas de las obras de Judy Chicago, en particular con la pieza objetual e instalativa Dinner Party, que involucra una representación de distintas mujeres importantes en la historia, acudiendo a estilizaciones de genitales femeninos en platos servidos en una mesa, con la copa o el cáliz re-significados junto a una jerga visual que mira también hacia representaciones arquetípicas. Cabe destacar, del mismo modo, que existe un sin número de artistas que se exploran su rol social a través del atrevimiento de la representación de su cuerpo.

Finalmente, retomando el concepto de ritual asociado con el arte, el cuerpo y lo femenino, un referente indispensable es Ana Mendieta, en donde sus performances están vinculados a la unión con la tierra y los elementos cosmogónicos, la sangre y al cuerpo como contenedor de vida y muerte en un ciclo eterno de la naturaleza.

Donald Kuspit en su artículo "Ana Mendieta, cuerpo autónomo" hace relación de estos elementos con su trabajo: "Mendieta se identifica con la Madre Tierra -se funde con ella en un apasionado abrazo místico, una llamada «experiencia oceánica» en parte por razones «regresivas» en parte por razones «creativas»" (1996). De acuerdo con la cita anterior, es posible resaltar la relación existente entre en trabajo de Mendieta y el paradigma de la tranquilidad y el sistema nocturno de Gilbert Durand, muy cercano a la experiencia que se quería lograr en el proyecto instalativo que se planteó en este artículo.

Ahora bien, más allá de una preocupación reivindicativa propia de los trabajos de las artistas feministas que cité, el proyecto de esta instalación deja planteada una inquietud de rescatar la memoria colectiva, esperando que el espectador reencuentre en su interior memorias primigenias vinculadas a ser y a estar viviendo dentro de un cuerpo biológicamente femenino; algo que no podemos obviar, pues todos habitamos en un tiempo inicial dentro de la corporalidad de una madre. Esta inquietud invita al ser humano a incorporar en su interior el vínculo equilibrado entre su animus y su anima, su ser masculino y femenino integrado en su psique, en la memoria de su origen, más allá 


\section{Artículos}

de tener una etiqueta o catalogación de género. En ese ser femenino que nos habita, que supera ese cuerpo que nos contiene $y$ que puede avistar a un pensamiento lateral, se encuentra más cercano a la intuición, al matriarcado, a la diosa mítica presente pero dormida en todos nosotros.

"El mito por tanto es una manifestación cultural que expresa un modelo mental"

Leach Edmun (1987).

\section{Referencias}

Baring, A. y Cashford, J. (2005). El mito de la diosa. México: FCE.

Bercker, U. (1997). Enciclopedia de los símbolos. México D. F: Editorial Océano de México, S. A. de C. V.

Cabello, P. (1995). La mujer en torno a la menopausia en el arte y la cultura indígenas americanas. Revista Anales. Museo de América,3. Recuperado de http://www. red-redial.net/revista-anales,museo,de,america-12-1995-0-3.html

Calvo, Y. (2004). Éxtasis y Ortigas, Costa Rica: Farben Norma, S.A.
Eliade, M. (2005). Tratado de historia de las religiones. México D.F: Ediciones Era, S.A. de C. V.

Hernández, F. (1998). Estética artificial: por qué algo es bello, cómo se crea la belleza. San José, C. R.: Mithoz.

Husain, S. (2001). La diosa, creación, fertilidad y abundancia mitos y arquetipos femeninos. Singapur: TASCHEN.

Jung, C. G., Franz, M., Henderson, J., Jacobi, J. \& Jaffe, A. (1995). El hombre y sus símbolos (Trad. Escolar L.). Man and his simbols. (1era edición). España: Ediciones Paidós.

Kuspit, D. (1996). Ana Mendieta, Cuerpo autónomo. En G. Moure, (Ed.), Ana Mendieta, pp. 35-63. Compostela: Centro Galego de Arte Contemporánea. Xunta de Galicia.

Mardones, J. M. (2000). El retorno del mito: la racionalidad mito-simbólica. Madrid: Editorial Síntesis.

Marín, A. (2007). "La ruta de la Luna" Explorando en los arquetipos de vitalidad, cuerpo y espíritu en lo femenino. [Tesis de maestría]. Universidad Veritas, Costa Rica.

Warr, Tracey (ed.) (2006). El cuerpo del artista. Barcelona: Phaidon. 